\title{
A Mixed Methods Study of Health and Social Disparities Among Substance-Using African American/Black Men Who Have Sex with Men
}

\author{
Mance E. Buttram • Steven P. Kurtz
}

Received: 18 March 2014 / Revised: 11 July 2014 / Accepted: 23 July 2014 /Published online: 15 August 2014

(C) W. Montague Cobb-NMA Health Institute 2014

\begin{abstract}
African American/Black men who have sex with men (MSM) in the USA experience health and social disparities at greater rates than MSM of other races/ethnicities, including HIV infection and substance use. This mixed methods paper presents: (1) a quantitative examination of health and social disparities among a sample of substanceusing African American/Black MSM $(N=108)$ compared to Caucasian/White MSM $(N=250)$ and (2) in-depth qualitative data from a subsample of African American/Black MSM ( $N=$ $21)$ in order to contextualize the quantitative data. Findings indicate that compared to Caucasian/White MSM, African American/Black MSM experienced a wide range of health and social disparities including: substance use and dependence; buying, trading or selling sex; educational attainment; employment; homelessness; identifying as gay; HIV status; arrest history; social support; and satisfaction with one's living situation. Qualitative data suggests that structural interventions that address homophobia and the social environment would be likely to mitigate many of the health and social disparities experienced by African American/Black MSM.
\end{abstract}

Keywords Substance use $\cdot$ HIV risk $\cdot$ Syndemic $\cdot$ Men who have sex with men

\section{Introduction}

Syndemic production of health disparities, defined as two or more risk factors that interact synergistically and contribute to

M. E. Buttram $(\bowtie) \cdot$ S. P. Kurtz

Center for Applied Research on Substance Use and Health

Disparities, Nova Southeastern University, Ft. Lauderdale, FL, USA

e-mail: mance.buttram@nova.edu an excess burden of disease in a population, is a concept that is focused on viewing health as the possession of complete physical, mental, and social well-being that must be evaluated within a larger sociocultural context [1]. Over the past several years, the syndemic framework has played a significant role in examinations of HIV, substance use, violence, mental health problems, and other social and health disparities among men who have sex with men (MSM) in the USA [2-10].

However, much of the research examining health disparities among MSM using a syndemic framework has focused on structural homophobia and institutionalized stigma, with a concentration on predominately White MSM, and has largely ignored subgroups of MSM differentiated by race/ethnicity [2]. While much research among African American/Black MSM has examined associations between substance use and HIV transmission risk [11-13], syndemic-focused research among African American/Black MSM is still scant [2]. This is in spite of indications that African American/ Black MSM may experience even greater health and social vulnerabilities than other MSM due to multiple marginalizations.

Literature indicates that African American/Black MSM experience greater rates of HIV incidence and prevalence, and a host of other syndemic health and social disparities, including substance use, victimization and gang involvement, incarceration, and poor physical health compared to other MSM [12-18]. Moreover, African American/Black MSM are subject to additional structural inequalities such as poverty, lack of adequate education, discrimination, and incarceration that are specific to African American/Black populations in the USA [19-24].

Structural homophobia is well documented within African American society [25], and it has been suggested that health 
inequalities among African American/Black MSM, such as HIV infection and victimization, may also be attributable to homophobia and stigma within African American society [13, 16]. As a result, African American/Black MSM are less likely to disclose their sexual orientation or same-sex behaviors, and are more likely to be exposed to heterosexist community, family, and religious norms [26, 27]. Further, African American/Black MSM are less likely to have access to adequate social support [16], which may in part be due to messages against homosexuality and stigma disseminated by many African American churches and religious African American families [28, 29]. The absence of social support is associated with experiences of discrimination, financial hardship, and participation in risky sexual situations [30], while the presence of social support is associated with lower substance use and sexual risk behavior among African American/ Black MSM [27, 31].

Given the literature documenting syndemic health and social disparities among MSM and evidence of additional vulnerabilities experienced by African American/Black MSM, this paper is guided by the hypothesis that, as racial/ethnic minority MSM, African American/Black MSM do in fact experience greater syndemic health and social disparities, compared to Caucasian/White MSM. First, we compare samples of substance-using African American/Black MSM and Caucasian/White MSM on survey measures of demographics, substance use, sexual behavior, syndemic disparities, structural inequality indicators, and social environment. Guided by these findings, we present qualitative interview data from a sample of substance-using African American/Black MSM to provide additional context to these analyses and to describe men's lived experiences with syndemic health disparities. Understanding the syndemic disparities among African American/Black MSM is essential to improving and sustaining the health of this population, especially regarding HIV transmission risk [1]. Thus, the paper concludes with a discussion of the implications of these findings for HIV transmission risk reduction interventions.

\section{Methods}

Site

The Miami-Ft. Lauderdale metropolitan area is a wellknown migration destination for MSM, with the second highest proportion of same-sex households among large cities in the nation [32]. The area reports the highest HIV and AIDS incidence rates in the USA [33]. A recent Miami study found that $45 \%$ of HIV-positive MSM were unaware of their infection [18].
Quantitative Sample

\section{Procedures}

Quantitative data were collected from baseline assessments of African American/Black $(N=108)$ and Caucasian/White $(N=$ 250) MSM who participated Project ROOM, a risk reduction intervention trial conducted in the Miami-Fort Lauderdale, Florida metropolitan area. Project ROOM was a two-armed randomized controlled trial (RCT) testing the efficacy of an empowerment theory-based small group intervention compared to a resilience theory-based single session counseling condition. Eligible men were between ages 18 and 55; reported recent (past 90 days) unprotected anal intercourse (UAI) with a nonmonogamous partner(s); and met one or more of three substance use criteria - binge drinking (five or more drinks) at least three times in the past month, using marijuana on 20 or more days in the past month, or using any other drug at least three times in the past month. Participants were eligible regardless of HIV status.

Participants were recruited to Project ROOM between November 2008 and October 2010 through multiple methods including direct outreach, participant referral, and internet and print media. In total, 2,330 men called the study field office to be screened for eligibility, with 711 men being initially eligible, and 515 men ultimately participating in the study [34]. Men responding to recruitment messages called the field office and were screened to determine eligibility, including direct questions about number of recent days of substance use and recent UAI frequency. Follow-up interviews completed in December 2011. A full description of Project ROOM has been fully described elsewhere including the study site, measures, sample, recruitment, procedures, interventions, and outcomes [34].

\section{Survey Measures}

Demographics Demographic measures included age at the time of study enrollment.

Substance Use and Sexual Behaviors The Global Appraisal of Individual Needs (GAIN, v. 5.4) [35] was the primary component of the standardized baseline assessments. This instrument has eight core sections (background, substance use, physical health, sexual risk behaviors, mental health, social support and environment, criminal justice involvement, and education/work/financial responsibility), with each containing questions on the recency of problems, breadth of symptoms, and recent (past 90 days) and lifetime prevalence in days or times as well as lifetime service utilization. Substance use measures included past 90 days frequency of use of a variety of substances, including alcohol, marijuana, illicit drugs, and the misuse of prescription medications. Participants 
were also asked to use a calendar to calculate the number of days they were either drunk or high all or most of the day, regardless of the substance(s), during the past 90 days. In addition, for each substance used during the past 90 days, participants were asked how many times that substance was used within 2 hours before or during sex. For the latter measure, the numbers of times each substance was used were summed and reported here as the frequency of drugs used during sex.

The instrumentation was supplemented with an extensive battery of sexual behavior questions specific to MSM, including counts of past 90 days sexual intercourse partners and UAI. Additional questions asked if, during the past 90 days, a respondent had "used money or drugs to purchase or get sex" (buying sex) and whether he had "traded sex to get drugs, gifts, or money" (trading or selling sex). Participants also reported if they had had sexual intercourse with women during the past year.

Syndemic Disparities Measures of syndemic disparities in the GAIN instrumentation included mental distress, substance dependence, and victimization. The General Mental Distress Scale (GMDS) is comprised of past year Diagnostic and Statistical Manual of Mental Disorders (DSM-IV) symptom counts for depression (9 items), anxiety (12 items), and somatic disorders (4 items). This scale is reducible to classifications indicating clinical significance (subclinical, moderate, and severe) [35] and was further dichotomized in the analyses presented here into "severe" and "not severe." Substance dependence was assessed by the endorsement of three or more of seven DSM-IV criteria in the past year (e.g., needing more drug to get the same effect, experiencing withdrawal symptoms, and being unable to quit or cut down). Lastly, victimization was assessed by affirmative responses to the following events: being attacked with a weapon or being beaten so as to cause bruises, cuts, or broken bones (physical abuse); being forced to participate in sexual acts against one's will (sexual abuse); or being made to feel very bad about oneself or one's life (emotional abuse). For analysis, responses were summed and dichotomized - any lifetime abuse vs. no abuse.

Structural Inequality Indicators Structural inequality indicators included in the GAIN [35] instrumentation were measured by years of education (presented as " 12 or more years" and "16 or more years" in Table 1), full-time employment status, and whether they had been homeless in the past year. Gay identity was assessed by asking participants, "What do you consider your sexual identity to be?" Responses were dichotomized as gay identifying versus not. Participant HIV status was assessed by self-report, and seropositivity was verified with a notice of diagnosis or ARV prescription. Arrest history was assessed by the question, "In your lifetime, about how many times have you been arrested, charged with a crime, and booked?" This measure was dichotomized into any lifetime arrest versus not.

Social Environment Social environment measures included social support, which was based on the Social Support Questionnaire [36], using questions specifically adapted for this population. Thus, social support was measured with a fiveitem inventory in which respondents listed from zero to nine people who would offer help or support for each item (e.g., "Whom can you really count on to let you live with them if you lost your housing?"; "Whom can you really count on to help you if you had a health crisis?"). Participants were then asked to rate their level of satisfaction with the support available to them for each item on a six-point scale ranging from "very dissatisfied" to "very satisfied." The people listed for all questions were summed to generate the inventory of the total number of people offering support, ranging from 0 to 45 . Similarly, the responses to participant satisfaction with social support were aggregated to generate the total level of satisfaction (ranging from 0 to 25 ).

The GAIN [35] measures of availability and utilization of emotional support from others was assessed by asking participants to rate their recent coping behavior when under stress by responding to this statement, "I have been getting help and emotional support from other people," using a four-point scale from "I've been doing this a lot" to "I haven't been doing this at all." Responses were dichotomized such that "a lot/moderately" indicated getting emotional support and "a little/not at all" indicates not. As an indicator of satisfaction with current living situation, participants were asked if they were either satisfied or not with where they are living.

Analyses

Analyses of the survey data were conducted using IBM SPSS version 21. Descriptive statistics were calculated for variables of interest. Significance tests of differences between African American/Black and Caucasian/White MSM were calculated using ANOVA tests for continuous measures and Pearson's chi-square tests for categorical variables.

\section{Qualitative Subsample}

\section{Procedures}

To contextualize the survey data and to better understand African American/Black men's experiences with syndemic health and social disparities, in-depth interviews were conducted among 21 African American/Black MSM who completed Project ROOM. Men who completed Project ROOM were contacted via phone or e-mail and asked to participate in a qualitative interview. A total of 21 men agreed to be 
interviewed. Qualitative interviews were guided by a semistructured protocol asking about men's experiences with substance use and sexual behavior, and the social context in which these behaviors occurred. Each interview lasted approximately $90 \mathrm{~min}$, and participants were compensated $\$ 50$ for their time and travel expenses. Research protocols were approved by the Institutional Review Boards at Nova Southeastern University and Florida International University.

\section{Analyses}

Qualitative interviews were transcribed and coded using descriptive and in vivo coding schemes [37] using ATLAS.ti, version 7 software. Qualitative data analyses were guided by grounded theory, which is the process by which each interview is coded and analyzed using an inductive process grounded in participants' voices and later linked together to form formal themes and concepts [38]. A basic principle of the grounded theory approach is that interviews are conducted to the point of saturation, meaning no new insights are gleaned from the data [38]. Previous research has shown that saturation can be reached after as few as 12 interviews [39].

\section{Results}

Project ROOM Survey Data

\section{Demographics and Syndemic Health Disparities}

Results for demographics and syndemic health disparities are shown in Table 1. On average, African American/Black MSM from Project ROOM were approximately 2 years younger than Caucasian/White MSM (39.3 vs. $42 ; p=0.008)$.

Rates of binge drinking (five or more drinks at one sitting) and the misuse of prescription sedatives and opioids in the past 90 days did not significantly differ by race/ethnicity. Compared to Caucasian/White MSM, Black men were more likely to report marijuana ( 75.9 vs. $60.0 \%$; $p=0.004$ ), powder cocaine (59.3 vs. $35.6 \% ; p<0.000)$, crack cocaine ( 40.7 vs. $15.6 \% ; p<0.000)$, and ecstasy use (27.8 vs. $14.8 \% ; p=$ $0.004)$. Caucasian/White men were more likely to use methamphetamine (28.4 vs. $13.0 \% ; p=0.002)$ than African American/Black MSM. However, African American/Black MSM from Project ROOM reported nearly two and a half times the number of days high/drunk (34.4 vs. $14.0 ; p<0.000$ ) and nearly double the number of times drugs were used during sex (77.7 vs. $40.2 ; p<0.000)$ compared to Caucasian/White men.
The mean numbers of sex partners and unprotected sex frequency were not significantly different for Black and White MSM. Buying sex during the past 90 days was nearly three times more prevalent among African American/Black MSM (49.1\%) compared to Caucasian/White MSM (17.6\%; $p<0.000$ ). The rate of African American/Black MSM who traded or sold sex during the past 90 days was also higher (36.1\%) compared to Caucasian/White MSM (18.4\%; $p<0.000$ ).

More African American/Black men met the criteria for substance dependence $(42.6$ vs. $24.0 \% ; p<0.000)$ than Caucasian/White men. African American/Black MSM and Caucasian/White MSM did not differ on other syndemic variables.

\section{Structural Inequality Indicators}

African American/Black MSM were less likely to report high school completion ( 82.4 vs. $92.8 \% ; p=0.003$ ) or 4 or more years of college ( 14.8 vs. $40.0 \%$; $p<0.000)$ than White men. The rate of African American/Black men who reported working full time (11.1 vs. $30.4 \%$; $p<0.000)$ was less than that of Caucasian/White men. Past year homelessness was more likely to be reported by African American/Black MSM compared to Caucasian/White MSM (44.4 vs. $21.2 \% ; p<0.000$ ) as was arrest history ( 82.4 vs. $60.4 \% ; p<0.000$ ).

The rate of African American/Black men endorsed gay identity was lower compared to that of Caucasian/White men $(58.3$ vs. $90.8 \% ; p<0.000)$. HIV-positive serostatus was more prevalent among African American/Black MSM than Caucasian/White MSM (63.9 vs. $46.4 \%$; $p=0.002$ ).

\section{Social Environment}

The mean number of people available for social support among African American/Black MSM was 12 (SD, 8.5; range, 0-45) compared to more than 17 for Caucasian/White MSM (SD, 10.3; $p<0.000)$. African American/Black MSM were less likely to report coping by getting help and emotional support from others (38 vs. $52.8 \% ; p=0.010)$ and being satisfied with their living situation (64.8 vs. $76.4 \%$; $p=$ 0.024) compared to Caucasian/White men.

\section{Qualitative Data}

\section{Syndemic Health Disparities}

Participants described using a range of substances, including alcohol, marijuana, cocaine, and crack cocaine. Eligibility criteria ensured that all participants were heavy substance users; however, during the qualitative interview which took place following study completion, none of them seemed to truly enjoy alcohol or drug use. As one participant said, 
Table 1 Comparison of characteristics by race/ethnicity $N=358$

\begin{tabular}{|c|c|c|c|c|c|c|}
\hline & \multicolumn{2}{|c|}{ Black MSM } & \multicolumn{2}{|c|}{ White MSM } & \multirow[t]{2}{*}{ Chi-square or $F$ statistic } & \multirow[t]{2}{*}{$P$} \\
\hline & $N=108$ & $30.2 \%$ & $N=250$ & $69.8 \%$ & & \\
\hline $\mathrm{Age}^{\mathrm{a}}$ & 39.3 & $(9.1)$ & 42.0 & $(8.546)$ & 7.185 & 0.008 \\
\hline \multicolumn{7}{|l|}{ Substance use behavior (past 90 days) } \\
\hline Alcohol (binge drinking) & 89 & $82.4 \%$ & 208 & $83.2 \%$ & 0.034 & 0.855 \\
\hline Marijuana & 82 & $75.9 \%$ & 150 & $60.0 \%$ & 8.387 & 0.004 \\
\hline Cocaine (powder) & 64 & $59.3 \%$ & 89 & $35.6 \%$ & 17.251 & 0.000 \\
\hline Crack cocaine & 44 & $40.7 \%$ & 39 & $15.6 \%$ & 26.767 & 0.000 \\
\hline Methamphetamine & 14 & $13.0 \%$ & 71 & $28.4 \%$ & 9.926 & 0.002 \\
\hline Ecstasy & 30 & $27.8 \%$ & 37 & $14.8 \%$ & 8.350 & 0.004 \\
\hline Prescription sedative misuse & 31 & $28.7 \%$ & 90 & $36.0 \%$ & 1.794 & 0.180 \\
\hline Prescription opioid misuse & 26 & $24.1 \%$ & 68 & $27.2 \%$ & 0.381 & 0.537 \\
\hline Days drunk/high all or most of the day & 34.4 & $(33.6)$ & 14.0 & $(22.96)$ & 44.245 & 0.000 \\
\hline Drugs used during sex frequency ${ }^{a}$ & 77.7 & $(97.4)$ & 40.2 & $(49.60)$ & 23.157 & 0.000 \\
\hline \multicolumn{7}{|l|}{ Sexual Behavior (past 90 days) } \\
\hline Partners $^{\mathrm{a}}$ & 14.7 & $(21.2)$ & 13.2 & $(18.86)$ & 0.440 & 0.508 \\
\hline Unprotected sex times $^{\mathrm{a}}$ & 27.8 & $(51.0)$ & 20.8 & $(27.54)$ & 2.764 & 0.097 \\
\hline Buying sex & 53 & $49.1 \%$ & 44 & $17.6 \%$ & 37.822 & 0.000 \\
\hline Trading or selling sex & 39 & $36.1 \%$ & 46 & $18.4 \%$ & 13.066 & 0.000 \\
\hline \multicolumn{7}{|l|}{ Syndemic disparities } \\
\hline Severe mental distress & 63 & $58.3 \%$ & 141 & $56.4 \%$ & 0.115 & 0.735 \\
\hline DSM-IVR substance dependence & 46 & $42.6 \%$ & 60 & $24.0 \%$ & 12.509 & 0.000 \\
\hline Victimization history & 83 & $76.9 \%$ & 212 & $84.8 \%$ & 3.286 & 0.070 \\
\hline \multicolumn{7}{|l|}{ Structural inequality indicators } \\
\hline Education -12 or more years & 89 & $82.4 \%$ & 232 & $92.8 \%$ & 8.790 & 0.003 \\
\hline Education -16 or more years & 16 & $14.8 \%$ & 100 & $40.0 \%$ & 21.841 & 0.000 \\
\hline Work full time & 12 & $11.1 \%$ & 76 & $30.4 \%$ & 15.136 & 0.000 \\
\hline Homeless (past year) & 48 & $44.4 \%$ & 53 & $21.2 \%$ & 20.120 & 0.000 \\
\hline Identify as gay & 63 & $58.3 \%$ & 227 & $90.8 \%$ & 51.667 & 0.000 \\
\hline HIV positive & 69 & $63.9 \%$ & 116 & $46.4 \%$ & 9.237 & 0.002 \\
\hline Arrest history & 89 & $82.4 \%$ & 151 & $60.4 \%$ & 16.531 & 0.000 \\
\hline \multicolumn{7}{|l|}{ Social environment } \\
\hline Number of people available for support ${ }^{\mathrm{a}, \mathrm{b}}$ & 12.0 & $(8.5)$ & 17.2 & $(10.3)$ & 21.664 & 0.000 \\
\hline Satisfaction with available support ${ }^{\mathrm{a}, \mathrm{c}}$ & 16.9 & $(7.1)$ & 18.0 & $(6.3)$ & 2.095 & 0.149 \\
\hline Getting emotional support from others & 41 & $38.0 \%$ & 132 & $52.8 \%$ & 6.648 & 0.010 \\
\hline Satisfied with living situation & 70 & $64.8 \%$ & 191 & $76.4 \%$ & 5.124 & 0.024 \\
\hline
\end{tabular}

${ }^{\mathrm{a}}$ Mean; SD

${ }^{\mathrm{b}}$ Range, 0-45

${ }^{\mathrm{c}}$ Range, 0-25

"Drugs are not fun. Whoever tells somebody drugs are fun is lying. Drugs are not fun." Implicit in this statement is a feeling of fatigue, as nearly all participants described drugs and alcohol having been a part of their lives for many years. Often drugs and alcohol were present from a very early age. When asked to describe his family, one participant described his childhood in this way, "My family is kind of, like, either they're uppity with their nose in the air, or they're like, drug addicts." This participant went on to say:

Growing up [drugs] was all I seen. My mom, like, my mom worked pretty much all the way to her death, so from 10 to about 16, 17, I was always home by myself, or she'll have [my family] over there to, like, babysit me. Well, what she don't know is they were smoking 
weed and smoking crack inside of her house, so growing up that's all I seen was drug abuse, alcohol... My mom was an alcoholic, so drug abuse, alcohol abuse, so... It got to the point where I think now that subconsciously it's like, "Oh, this is a normal thing to do."

Over the course of their substance use careers, men began to make connections between alcohol and drug use and HIV risk. This theme emerged when the men were asked to describe their use of alcohol or drugs. As was stated during one interview, "You know something? When I get high, I'm more likely to have unprotected sex. It's like one plus one equals two." None of the participants discussed substance use and HIV in terms of a syndemic, but the concept was a daily lived experience that the men knew very well. Thinking about other African American/Black MSM he has known, one young Project ROOM participant described it this way:

I started on alcohol, I went to weed, from weed I went to cocaine, from cocaine I went to partying every night, maybe not so much as all the time unprotected sex, but most of the time unprotected sex, and then I could have very easily went... There was only two more steps: crack and... bam [HIV]. So that's why, like, if the circumstances would have changed, if the moon would have aligned just right, it could have easily have been me.

A majority of participants saw the negative consequences of substance use from an early age. Moreover, there was an awareness that substance use, especially crack cocaine, seemed to lead to an HIV-positive diagnosis for many men.

Men also connected mental and psychosocial problems, including loneliness, depression, and stigma or discrimination based on sexual orientation or same-sex behavior to substance use. For example, participants described being on the "down low," such that men actively concealed their sexual behaviors, and used alcohol and drugs to cope with feelings of inadequacy. As one man stated, "Drugs are used to fill the void of loneliness associated with being gay and to deal with the gay issue. It's a way for us to let down our inhibitions." In the words of another participant, "Black gay guys have no outlet, except maybe drugs, because there's no acceptance. Drugs and depression go hand in hand." Like the syndemic nature of substance use and HIV risk, men were also aware of the interconnectedness of substance use and other mental, emotional, or psychological problems they were facing.

In addition to using alcohol or drugs, "buying" or "trading or selling" sex in exchange for money or drugs were mentioned by four participants as coping behaviors, two of whom had histories of sex trading. One participant described low self-esteem and feelings of being unwanted as facilitating his belief that he could only meet men through an exchange of drugs for sex. Another participant described selling sex as a way of "healing" from life's disappointments or limitations and from feeling pain. Both men, however, also described the excitement associated with it. "I had a 9 to 5 and I wanted excitement. It was a way to feel hot or wanted, to do something wild," said one man. In the words of another, "I didn't know of it in Georgia. When I came down here, I found it fascinating, how easy it was, the choices, the variety. I was almost overwhelmed with excitement." Though not all men reported "buying" or "trading or selling" sex, it was noted by one participant that if someone is using drugs and in a relationship, trading sex is essentially what he is doing, whether he admits it or not.

Participants' use of alcohol, drugs, or sex to cope with mental health problems or stigma was a cycle for many participants. Yet, some participants had additional need for substance use as a coping mechanism. Victimization, particularly childhood victimization was described by three participants. The desire to numb these feelings with substance use, in addition to other stressors, was seen as necessary to survive.

\section{Structural Inequality Indicators}

Structural inequalities experienced within African American communities also weighed heavily on many men. These also impacted substance use behaviors. Several participants described feelings of stress induced by a lack of money, jobs, and healthcare, which in turn led to coping behaviors based on alcohol and drug use. One participant said, "Black guys have more hardships; White and Hispanic guys have jobs, healthcare." Another participant described himself upon enrolling in the Project ROOM study in this way, "Usually I would've been like, “Aw, man, I ain't got no job. How am I gonna pay these bills?" and that would have drove me to, like, get high and drink, and, like, drink it all away." While this was a theme that emerged during the interviews, some men described more severe problems than others:

I feel inadequate in pretty much every situation. I mean everybody - you listen to everybody and they talk about their jobs and the kind of house they have, the kind of car they drive. And you're on the bus. You're renting an apartment. You're on Social Security disability. You're HIV-positive. You know, that kind of thing.

All men participating in the qualitative interviews currently described themselves as gay. However, the majority of men described openly identifying as gay or portraying oneself as gay in the African American community as unacceptable and potentially dangerous. "You mention the word 'gay' and the next thing you know, you're ousted," said one participant. He went on to say, regarding not identifying as gay, that "You avoid a lot of the fights. You avoid the possible conflict." This 
theme was echoed by nearly all men with reasons for such attitudes ranging from churches that describe same-sex behavior as sinful, to the influence of slavery in which African American men were historically emasculated, leading to the development of a hypermasculine persona. Participants stated that the avoidance of being identified as gay causes many men to also have sex with women or to embrace a "down low" identity.

Similar to experiences of African American/Black men in other communities, men in the sample reported histories of arrest, jail, and juvenile detention. In these discussions, two subthemes emerged. In the first, participants told about intentionally breaking the law. For example, one young participant described being in and out of jail and juvenile detention centers for 5 years in this way, "You know, like anything that I do, I dedicate myself to it, and I do it well. So, when I was a badass, I got in trouble and I got in trouble pretty good." In the second subtheme, participants told of not breaking the law and being punished for crimes they did not commit. For instance, one participant, stated, "I was 15 years old, did 13 years for a crime I didn't commit, and it was a sex charge. And, like I said, I didn't commit it, but my family was poor, I was poor, we could only afford a public defender, and that's what happened." The consequences of criminal justice system involvement by African American/Black MSM were known by all men, which included limited educational and employment opportunities, mental distress, and increased substance use as a coping behavior.

\section{Social Environment}

The social environment of participants affected many aspects of their lives. One participant described the process of choosing friends based on what a potential friend could offer, "The people I would search out would be drug addicts, alcoholics, partiers, because I'm like, “Okay, I don't have a car, but if I get with this person and they wanna go out, I've got a ride to the club and back," or, you know, "Maybe if I run out of money, this person's got the same habit I do. So maybe they'll have something and I'll go over to their house." Another participant described himself as being, "not the most savvy" when it came to alcohol and drug use, however, his social circle was heavily involved in it and influenced his substance use and his access to drugs. Because of substance-use-centered relationships such as these, a majority of participants described a lack of social support within their family and friendship networks. While some participants mentioned having insufficient material support, a majority described being in need of emotional support. Given the stigma and discrimination associated with same-sex behavior in many African American communities, many participants did not have anyone to talk to about such problems, feelings, or emotions. As one participant described:
If you give a black guy support, they'll be your friend for life...it's not always money support either. Somebody to talk to, somebody to be there, and somebody to hang out with that's positive, other than, like, what they're use to - the drugs, the alcohol, the gangbangers, the thugs, the criminals - you know, somebody positive.

The biggest reason African American/Black MSM from Project ROOM were not satisfied with their current living situation was related to their financial circumstances. Participants reported living in undesirable neighborhoods or apartments or with objectionable people because they did not have the financial freedom to go elsewhere. One participant living in Miami Beach described the city as "not cheap" and "a great place to be if you have money." He, on the other hand, was unable to find work and described it as "an economically difficult time." Another participant told about his small, affordable housing unit in downtown Miami. It was here that he began interacting with "partier-types" of people, which had a major impact on his behavior. In addition, many men reported histories of bad living situations from which they eventually removed themselves. In particular, one participant grew up in Miami's Liberty City neighborhood and has vivid memories of riots, seeing many of his friends go to jail, poor schools, and a host of daily struggles. Another man described his living situation in the Overtown neighborhood of downtown Miami. The rampant drugs and violence, including the shooting of a 4-year-old girl, contributed to his mental distress and feelings of insecurity. Though, for several years, he could not afford to go elsewhere, he moved away as soon as he was able. Still others told of growing up in racially segregated neighborhoods in northern cities before eventually moving to South Florida.

\section{Discussion}

Results from this paper represent the first apparent study to utilize both quantitative and qualitative data to formally describe the extent of syndemic health and social disparities, structural inequalities, and the social environment experienced by a sample of African American/Black MSM substance users. The survey data demonstrated that, compared to Caucasian/White men, African American/Black men experienced a wide range of health and social disparities of greater severity including: substance use and dependence; buying, trading, or selling sex; low levels of educational attainment and employment; homelessness; non-gay identification; HIV infection; arrest history; and low levels of social support and satisfaction with one's living situation.

Previous research has documented some of these associations, especially between substance use, HIV transmission 
risk, and structural homophobia and stigma among African American/Black MSM [11-13, 16, 30]. However, the present study illustrates the extent of health and social disparities among this sample of African American/Black MSM. While any one of these disparities can have a negative impact on a population, the high prevalence of such a great number of these factors is especially worrisome.

During in-depth interviews, African American/Black participants from Project ROOM described the connection between substance use and HIV transmission risk behaviors. Further, they described substance use and HIV transmission risk as being connected to mental health problems, stigma, homophobia, and lack of access to adequate employment, and as being highly visible components of their social environment. These findings cohere with existing research among African American/Black MSM [13, 16] and add additional evidence of the negative impact of structural homophobia on the health of these men.

As such, these qualitative findings point to specific opportunities for intervention from which to address HIV transmission risk. Structural interventions that reduce experiences with and exposure to homophobia would likely have positive outcomes for high-risk African American/Black MSM, not only with regard to HIV transmission risk behavior, but also substance use, mental health, and the social environment as well. Recent literature suggests that school-based interventions and social marketing campaigns challenging anti-gay stigma have positive impacts on health outcomes for MSM [40]. Similar strategies targeting African American communities would also likely have positive impacts on the health of high risk African American/Black MSM.

Given the syndemic nature of these health and social disparities, reductions in substance use and improvements in mental health and the social environment would further reduce HIV transmission risk among these men. Recent research among vulnerable African American/Black women suggests that addressing lack of education, transportation, and social support would likely positively impact HIV transmission risk [41]. In addition, data from Project ROOM demonstrate that substance use and HIV transmission risk are mediated by social support among African American/Black men [42]. Thus, interventions that address social support, as well as syndemic health and social disparities among high risk African American/Black MSM are likely to be effective in reducing HIV transmission risk as well.

This study has some limitations that must be noted. The ability to generalize the findings to other MSM is limited by the study eligibility requirements, including regular substance use and recent HIV transmission risk. Further, the data are based on self-report, potentially leading to underreporting of social undesirable behaviors. Given the high levels of substance use and sexual risk behaviors we found, however, the underreporting of these and other stigmatized behaviors would appear to be uncommon. We also note that the race/ ethnicity of participants' sex partners was not collected as part of this study, limiting our ability to analyze HIV transmission risk behavior by sex partner race/ethnicity.

Qualitative data can be subject to recall and social desirability bias as well as interviewer effects. However, the use of a trained, experienced interviewer likely mitigated this. Due to the relatively small sample size of substance-using men in the qualitative sample, the results presented here may not be generalizable to other African American/Black MSM. Further, many African American/Black MSM from Project ROOM were unable to be contacted for the final qualitative interview which took place more than a year following completion of Project ROOM. Thus, only men who had working phone numbers or e-mail addresses were able to participate in the qualitative portion of the study.

Despite these limitations, these data suggest that a riskreduction strategy tailored to high-risk African American/ Black MSM should focus on a wide range of syndemic health and social disparities related to substance use, HIV transmission risk, structural inequality, and the social environment. While several recent interventions studies target HIV transmission risk among African American/Black MSM [43-47], only two apparent studies that also address related health and social disparities, such as substance use and social support $[48,49]$. Research, interventions, and public health policy that do not address the syndemic nature of HIV transmission risk will miss critical points of intervention. Further, a focus on the larger sociocultural context of HIV transmission risk among African American/Black MSM will have beneficial effects on other aspects of health and well-being.

Informed Consent All procedures followed were in accordance with the ethical standards of the Responsible Committee on Human Experimentation (institutional and national) and with the Helsinki Declaration of 1975, as revised in 2000 (5). Informed consent was obtained from all participants for being included in the study.

Support This research was supported by an Early Career Investigator Award from the Center for Applied Research on Substance Use and Health Disparities and DHHS Grant Number 5 R01 DA024579 from the National Institute on Drug Abuse. The content is solely the responsibility of the author and does not necessarily represent the official views of the National Institute on Drug Abuse or the National Institutes of Health.

Conflict of Interest Statement Mance E. Buttram and Steven P. Kurtz declare they have no conflict of interest.

\section{References}

1. Singer M. Introduction to syndemics: a critical systems approach to public and community health. San Francisco: Jossey-Bass; 2009. 
2. Dyer TP, Shoptaw S, Guadamuz TE, et al. Application of syndemic theory to black men who have sex with men in the multicenter AIDS cohort study. J Urban Health. 2012;89(4):697-708.

3. Egan JE, Frye V, Kurtz SP, et al. Migration, neighborhoods, and networks: approaches to understanding how urban environmental conditions affect syndemic adverse health outcomes among gay, bisexual and other men who have sex with men. AIDS Behav. 2011;15 Suppl 1:S35-40.

4. Friedman MS, Marshall MP, Stall R, Cheong J, Wright ER. Gayrelated development, early abuse and adult health outcomes among gay males. AIDS Behav. 2007;12(6):891-902.

5. Klein H. Using a syndemics theory approach to studying HIV risk taking in a popoulation of men who use the Internet to find partners for unprotected sex. Am J Men's Health. 2011;5(6):466-76.

6. Kurtz SP. Arrest histories of high risk gay and bisexual men in Miami: unexpected additional evidence for syndemic theory. J Psychoactive Drugs. 2008;40(4):513-21.

7. Kurtz SP, Buttram ME, Surratt HL, Stall R. Resilience, syndemic factors, and serosorting behaviors among HIV-positive and HIVnegative substance-using MSM. AIDS Educ Prev. 2012;24(3):193205 .

8. Mustanski B, Garofalo R, Herrick A, Donenberg G. Psychosocial health problems increase risk for HIV among urban young men who have sex with men: preliminary evidence of a syndemic in need of attention. Ann Behav Med. 2007;34(1):37-45.

9. Parsons JT, Gov C, Golub SA. Sexual compulsivity, co-occurring psychosocial health problems, and HIV risk among gay and bisexual men: further eveidence of a syndemic. Am J Public Health. 2012;102(1):156-62.

10. Stall R, Mills TC, Williamson J, et al. Association of co-occurring psychosocial health problems and increased vulnerability to HIV/ AIDS among urban men who have sex with men. Am J Public Health. 2003;93(6):939-42.

11. Mimiaga MJ, Reisner SL, Fontaine Y-M, et al. Walking the line: stimulant use during sex and HIV risk behavior among Black urban MSM. Drug Alcohol Depend. 2010;110(1-2):30-7.

12. Tobin KE, German D, Spikes P, Patterson J, Latkin C. A comparison of the social and sexual networks of crack-using and non-crack using African American men who have sex with men. J Urban Health. 2011;88(6):1052-62.

13. Harawa NT, Williams JK, Ramamurthi HC, Manago C, Avina S, Jones M. Sexual behavior, sexual identity, and substance abuse among low-income bisexual and non-gay-identifying African American men who have sex with men. Arch Sex Behav. 2008;37(5):748-62.

14. Hatfield LA, Horvath KJ, Jacoby SM, Rosser BRS. Comparison of substance use and risky sexual behavior among a diverse sample of urban, HIV-positive men who have sex with men. J Addict Dis. 2009;28(3):208-18.

15. Garofalo R, Mustanski B, Johnson A, Emerson E. Exploring factors that underlie racial/ethnic disparities in HIV risk among young men who have sex with men. J Urban Health. 2010;87(2):318-23.

16. Mays VM, Cochran SD, Zamudio A. HIV prevention research: are we meeting the needs of African American men who have sex with men? J Black Psychol. 2004;30(1):78-105.

17. Prejean J, Song R, Hernandez A, et al. Estimated HIV incidence in the United States, 2006-2009. PLoS ONE. 2011;6(8):e17502.

18. Centers for Disease Control and Prevention. Prevalence and awareness of HIV infection among men who have sex with men: 21 cities, United States, 2008. Morb Mortal Wkly Rep. 2010;59(37):1201-7.

19. Bowleg L, Raj A. Shared communities, structural contexts, and HIV risk: prioritizing the HIV risk and prevention needs of Black heterosexual men. Am J Public Health. 2012;102(Supplement 2):S173-7.

20. DeNavas-Walt C, Proctor BD, Smith JC. Income, poverty, and health insurance coverage in the United States: 2011. Washington, DC: US Census Bureau; 2012.
21. Lim JR, Sullivan PS, Salazar L, Spaulding AC, DiNenno EA. History of arrest and associated factors among men who have sex with men. J Urban Health. 2011;88(4):677-89.

22. Bassuk EL, Buckner JC, Weinreb LF, et al. Homelessness in female headed families: childhood and adult risk and protective factors. Am J Public Health. 1997;87(2):241-8.

23. Susser E, Moore RA, Link B. Risk factors for homelessness. Am J Epidemiol. 1993;15(2):546-56.

24. Brondolo E, Gallo LC, Myers HF. Race, racism and health: disparities, mechanisms and interventions. J Behav Med. 2009;32(1):1-8.

25. Díaz RM, Peterson JL, Choi K-H. Social discrimination and health outcomes in African American, Latino, and Asian/Pacific Islander gay men. In: Wolitski RJ, Stall R, Valdiserri RO, editors. Unequal opportunity: health disparities affecting gay and bisexual men in the United States. New York: Oxford University Press; 2008. p. 327-54.

26. Balaji AB, Oster AM, Viall AH, Heffelfinger JD, Mena LA, Toledo CA. Role flexing: how community, religion, and family shape the experiences of young Black men who have sex with men. AIDS Patient Care STDS. 2012;26(12):730-7.

27. Maulsby C, Millett G, Lindsey K, et al. HIV among black men who have sex with men (MSM) in the United States: a review of the literature. AIDS Behav. 2014;18(1):10-25.

28. Fullilove MT, Fullilove RE. Stigma as an obstacle to AIDS action: the case of the African American community. Am Behav Sci. 1999;42(7):1117-29.

29. Peterson JL, Jones KT. HIV prevention for Black men who have sex with men in the United States. Am J Public Health. 2009;99(6):97680.

30. Ayala G, Bingham T, Kim J, Wheeler DP, Millett GA. Modeling the impact of social discrimination and financial hardship on the sexual risk of HIV among Latino and black men who have sex with men. Am J Public Health. 2012;102(Supplement 2):S242-9.

31. Lauby JL, Marks G, Bingham T, et al. Having supportive social relationships is associated with reduced risk of unrecognized HIV infection among black and Latino men who have sex with men. AIDS Behav. 2012;16(3):508-15.

32. Smith DM, Gates GJ. Gay and lesbian families in the United States: same-sex unmarried partner households: a preliminary analysis of 2000 United States Census data, a human rights campaign report. Washington, DC: Human Rights Campaign; 2001.

33. Centers for Disease Control and Prevention. Table 17. Reported AIDS cases and annual rates (per 100,000 population) by metropolitan statistical area of residence, 2006, 2007, and cumulative-United States and Puerto Rico. 2009; http:// www.cdc.gov/hiv/surveillance/resources/reports/2007report/ table17.htm. Accessed 17 Mar 2014.

34. Kurtz SP, Stall RD, Buttram ME, Surratt HL, Chen M. A randomized trial of a behavioral intervention for high risk substance-using MSM. AIDS Behav. 2013;17(29):2914-26.

35. Dennis ML. Global appraisal of individual needs. Version 5.4. Bloomington: Chestnut Health Systems; 2006.

36. Sarason IG, Levine HM, Basham RB, Sarason BR. Assessing social support: the social support questionnaire. J Pers Soc Psychol. 1983;44(1):127-39.

37. Saldaña J. The coding manual for qualitative researchers. Los Angeles: Sage; 2013.

38. Glaser BG, Strauss AL. Discovery of grounded theory: strategies for qualitative research. Hawthorne: Walter de Guyter; 1967.

39. Guest G, Bunce A, Johnson L. How many interviews are enough? An experiement with data saturation and variability. Field Methods. 2006;18:59-82.

40. Cahill S, Valadéz R, Ibarrola S. Community-based HIV prevention interventions that combat anti-gay stigma for men who have sex with men and for transgender women. J Public Health Policy. 2013;34(1): 69-81. 
41. Buttram ME, Surratt HL, Kurtz SP. Resilience and syndemic risk factors among African American female sex workers. Psychol Health Med. 2013;19(4):442-52.

42. Buttram ME, Kurtz SP, Surratt HL. Substance use and sexual risk mediated by social support among Black men. J Community Health. 2013;38(1):62-9.

43. Coleman CL, Jemmott L, Jemmott JB, Strumpf N, Ratcliffe S. Development of an HIV risk reduction intervention for older seropositive African American men. AIDS Patient Care STDS. 2009;23(8):647-55.

44. Koblin BA, Bonner S, Powell B, et al. A randomized trial of a behavioral intervention for Black MSM: the DiSH study. AIDS. 2012;26(4):483-8.

45. Peterson JL, Coates TJ, Catania JA, et al. Evaluation of an HIV risk reduction intervention among African-American homosexual and bisexual men. AIDS. 1996;10(3):319-25.
46. Williams JK, Glover DA, Wyatt GE, Kisler K, Liu H, Zhang M. A sexual risk and stress reduction intervention designed for HIVpositive bisexual African American men with childhood sexual abuse histories. Am J Public Health. 2013;103(8):1476-84.

47. Wilton L, Herbst JH, Coury-Doniger P, et al. Efficacy of an HIV/STI prevention intervention for Black men who have sex with men: findings from the many men, many voices (3MV) project. AIDS Behav. 2009;13(3):532-44.

48. Operario D, Smith CD, Arnold E, Kegeles S. The Bruthas Project: evaluation of a community-based HIV prevention intervention for African American men who have sex with men and women. AIDS Educ Prev. 2010;22(1):37-48.

49. Wu E, El-Bassel N, McVinney LD, et al. Feasibility and promise of a couple-based HIV/STI preventive intervention for methamphetamine-using, Black men who have sex with men. AIDS Behav. 2011;15(8):1745-54. 